Elisa Pires da Cruz Reale Caçapava

\title{
A FORMAÇÃO DO POLICIAL CIVIL DE SÃO PAULO EM DIREITOS HUMANOS: O CASO ACADEPOL
}

\author{
Dissertação de Mestrado \\ Professora Orientadora: Flávia Inês Schilling
}

Faculdade de Direito da USP 


\section{São Paulo - 2012}

\section{RESUMO}

O presente trabalho buscou entender como se dá a formação em direitos humanos dos policiais civis do Estado de São Paulo no atual contexto democrático, identificando algumas ações e limitações existentes para uma transformação da instituição nesse sentido. Desprovida de qualquer tentativa no sentido de detectar efeitos porventura gerados com essa formação, a investigação buscou apenas entender como acontece o processo de educação em direitos humanos na polícia civil de São Paulo e sentir se isso incomoda, inova ou cria novas possibilidades de atuação no cotidiano desses agentes. Para que isso fosse possível, foi utilizada uma série de instrumentos de pesquisa, dentre eles o estudo bibliográfico em livros, periódicos, sítios da internet, entre outros, para o levantamento e análise do que já se produziu sobre o tema; a análise do plano de ensino do curso de formação técnico profissional para investigador de polícia e para escrivão de polícia, ambos do ano de 2010, disponibilizados pela diretoria da ACADEPOL; e algumas falas de pessoas que trabalham pela formação em direitos humanos dentro da polícia. A dissertação está dividida em três grandes partes, sendo a primeira um estudo necessário sobre a polícia, incluindo um breve histórico e alguns apontamentos sobre os contornos atuais, mostrando um pouco mais sobre a instituição policial e a Academia de Polícia Civil do Estado de São Paulo. O segundo bloco trata de documentos importantes que colocaram a relação da segurança pública com os direitos humanos na agenda governamental e que direcionaram Estados a tomarem medidas em prol da formação de suas polícias. Por fim, o terceiro bloco consiste no estudo mais específico da educação em direitos humanos e da formação do policial, bem como na análise dos conteúdos programáticos disponíveis e das entrevistas realizadas no trabalho de campo.

Palavras-chave: Formação em direitos humanos; Polícia Civil de São Paulo; ACADEPOL. 


\section{INTRODUÇÃO}

Esta dissertação de mestrado tem como problema central a seguinte pergunta: como se dá a formação em direitos humanos dos policiais civis do Estado de São Paulo?

A escolha profissional pela pesquisa sobre os temas relacionados à segurança pública, e, a partir daí, a possibilidade de contatos com os dilemas da polícia civil em sua difícil relação com os direitos humanos, se deu por conta da paixão pelo enfrentamento das situações que se impuseram (e continuam se impondo) no dia-a-dia desde as primeiras experiências profissionais com o Direito e da relação com todos os sujeitos envolvidos no processo de aprendizado, unidos à percepção da importância de um mundo orientado pela visão dos direitos humanos.

A forma como o policial civil é visto pela sociedade, como ele trabalha, suas potencialidades, suas limitações, a responsabilidade que decorre dessa função, o trabalho tão complexo e diversificado que depende muito da subjetividade dos agentes no desempenho de suas tarefas cotidianas, entre outras questões, despertaram uma série de inquietações que enveredaram para as tentativas de conhecer melhor a formação do policial civil em direitos humanos, sem a preocupação de chegar à detecção dos efeitos porventura gerados com isso, mas, antes, sentir se isso incomoda, inova, cria novas possibilidades de atuação no cotidiano desses agentes. Daí esta dissertação, que trata sobre os direitos humanos na formação do policial civil de São Paulo, descrevendo o lugar que essa temática ocupa em sua formação, a partir do estudo do programa da ACADEPOL e de entrevistas com protagonistas dessa introdução na polícia civil.

E assim é que foi concebido o projeto que deu origem a este estudo, com a proposta de investigar a literatura disponível sobre o tema e de investir num estudo de caso, na ACADEPOL, para o exame dos conteúdos programáticos das disciplinas de direitos humanos e outras correlatas e de alguns dos sujeitos envolvidos na formação em direitos humanos do policial recém-chegado.

Com relação à trajetória metodológica, além da pesquisa bibliográfica, da garimpagem de informações em livros, periódicos, sítios da internet, entre outros, para o levantamento e análise do que já se produziu sobre o tema uma diversidade de instrumentos de pesquisa foi utilizada. 
O presente trabalho se caracteriza por ser um estudo de caso. Dentro da pesquisa qualitativa, exploratória e descritiva, o estudo de caso não necessariamente se caracteriza pela análise profunda de uma unidade; pode focar em um sujeito ou em uma situação particular. (NEVES, 1996) Nessa linha, o estudo não consiste na análise da Academia de Polícia - apesar de ser importante conhecê-la minimamente, bem como alguns de seus aspectos, como se tentou fazer ao longo do trabalho -, mas visou ao exame de um sujeito (o policial civil de São Paulo) numa situação bastante específica (a sua formação).

Para enriquecer o trabalho, a partir da coleta de dados relevantes que não seriam obtidos de outra forma, foram realizadas algumas entrevistas. As pessoas ouvidas foram criteriosamente escolhidas. São elas:

- $\quad$ Dr. Roberto Maurício Genofre;

- $\quad$ Dr. Tabajara Novazzi Pinto;

- $\quad$ Dr. José Pedro Zaccariotto; e

- Dr. Luis Fernando Camargo da Cunha Lima.

O Dr. Roberto Maurício Genofre é uma das pessoas mais conhecidas entre os policiais civis de São Paulo. Delegado de polícia aposentado, participou da elaboração da nova polícia na época do governo Montoro. Com as dificuldades políticas que surgiram, na época foi deslocado para a direção da Academia de Polícia, lugar de extrema importância e oportunidade para inserção da cultura de direitos humanos entre os policiais civis.

Dr. Genofre sempre esteve envolvido com a comunidade através de sua participação em grupos sociais, recebendo feedbacks no sentido de melhorar a polícia civil e a relação polícia civil / comunidade e sentindo necessidade de se envolver com a questão dos direitos humanos. Aproveitando a oportunidade da direção da ACADEPOL, que ocupou por duas vezes, desenvolveu algumas atividades significativas, dando espaço para que outro diretor, Dr. Tabajara Novazzi Pinto, pudesse inserir direitos humanos no rol de disciplinas ministradas para os cursos de formação da ACADEPOL.

Assim, como não poderia deixar de ser, um dos entrevistados foi o Dr. Tabajara Novazzi Pinto, responsável pela inserção da disciplina direitos humanos nos quadros da Academia. Além disso, foi ele também o criador do Centro de Direitos Humanos e Segurança Pública - CDHSP. Com sua saída da direção da ACADEPOL, reassumiu o 
Dr. Genofre, que o convidou para coordenar o CDHSP. Atualmente, é também ele quem coordena as atividades do grupo, além de sua ocupação funcional como chefe da assistência policial da Corregedoria de Polícia, apurando condutas de policiais violentos e corruptos, entre outras atividades.

Outro entrevistado foi o Dr. José Pedro Zaccariotto, Delegado assistente do Departamento de Polícia Judiciária do Interior - DEINTER 7, em Sorocaba. O Dr. Zaccariotto também esteve à frente do CDHSP, como coordenador, por algum período. Desenvolve atividades de formação policial no interior, em parceria com a Academia de Polícia e o Centro de Direitos Humanos, e produz trabalhos acadêmicos, dividindo suas experiências e divulgando informações de grande utilidade para policiais e sociedade em geral, como o recente livro A polícia civil e a defesa dos direitos humanos, coletânea que reúne instrumentos internacionais de proteção e promoção dos direitos humanos.

O quarto nome escolhido para as entrevistas foi o do Dr. Luis Fernando Camargo da Cunha Lima. Delegado atuante no CDHSP e titular da assistência policial civil da coordenação estadual dos CONSEGs, contribui sempre de forma muito produtiva para projetos de formação policial e educação em direitos humanos, de que é exemplo o Academia de Polícia Cidadã, elaborado pelo Dr. Zaccariotto com base em livro do Dr. Luiz Fernando sobre o Perfil Social do Crime.

Todos os entrevistados, com exceção do Dr. Genofre que já é aposentado, são professores da ACADEPOL e trabalham com a temática dos direitos humanos sempre de forma transversal. Pessoas que contribuíram muito para a elaboração do presente trabalho, dispuseram-se a dar suas impressões sobre a formação do policial civil em direitos humanos, além de outras contribuições valiosas, respondendo a um roteiro de perguntas, que será oportunamente apresentado. Por fim, todos concordaram em divulgar seus nomes, assinando um termo de consentimento livre e esclarecido. ${ }^{1}$

Além dessas falas, também foram analisados alguns documentos importantes para se compreender a formação do policial civil de São Paulo: o plano de ensino do curso de formação técnico profissional para investigador de polícia e para escrivão de polícia, ambos do ano de 2010, gentilmente cedidos pela diretoria da Academia de Polícia, à época ocupada interinamente pelo Dr. Cláudio Kiss. A Dra. Márcia Heloisa

\footnotetext{
${ }^{1} \mathrm{O}$ termo de consentimento livre e esclarecido é uma exigência do Comitê de Ética na Pesquisa por meio do qual o entrevistado concorda em participar como voluntário respondendo questões que se relacionam com o objetivo da pesquisa. Todos os entrevistados aceitaram terem seus nomes divulgados, dado o caráter público das funções.
} 
Mendonça Ruiz, professora da ACADEPOL disponibilizou, com a autorização da direção, cópias dos seus planos de ensino, que, segundo ela, são muito parecidos para todas as carreiras. O que diferencia uns dos outros, e que pode ser verificado nos dois cursos disponibilizados, é a quantidade de horas / aula de algumas disciplinas, conforme a necessidade para a carreira escolhida.

A questão aqui tratada é polêmica, mas ao mesmo tempo (e contraditoriamente) pouco discutida. Há um intenso debate sobre os direitos humanos no Brasil desde o final da ditadura militar; é tema que desperta interesse e paixão, ressurgindo em campanhas políticas, nos debates sobres os direitos sociais, econômicos, culturais, nas tensões entre a igualdade e a diferença, nas políticas de reconhecimento.

A Declaração Universal de Direitos Humanos de 1948 inspirou diversos países a adotarem em seus territórios legislações, documentos e políticas públicas voltados à proteção dos direitos humanos. Trata-se de um paradigma ético, surgido no contexto do pós-guerra como resultado de um sentimento de repúdio humano com relação às atrocidades e barbáries perpetradas naquele tempo.

O Brasil foi um deles e, assim, pode-se dizer que a importância dedicada à defesa dos direitos humanos em território nacional tem como contexto o fim da guerra fria, o avanço do processo de desenvolvimento econômico e social e as pressões internacionais em favor dos direitos humanos.

Mas não se pode esquecer que o Brasil ainda está em um processo de consolidação e institucionalização da promoção dos direitos humanos. Foi nas décadas de 1980 e 1990 que o Brasil realizou a progressiva inclusão da defesa da democracia e dos direitos humanos entre os principais objetivos do Estado e dos dirigentes políticos brasileiros, pois, em momento anterior, o estado de direito, a democracia e os direitos humanos sempre foram objetivos menores em relação à defesa do estado nacional e à promoção do desenvolvimento econômico. (MESQUITA NETO, 2010)

Deve-se ter em mente que a indignação pública e a mobilização da sociedade civil causada pelas violações de direitos humanos ocorridas durante o regime autoritário nas décadas de sessenta e setenta, que incluíram tortura, assassinato e desaparecimento de prisioneiros políticos e de oponentes do regime, foram fatores cruciais para a exigência do respeito aos direitos humanos. (MESQUITA NETO, 2010)

Sérgio Adorno (2010) explica que durante a transição para a democracia e por quase duas décadas a temática dos direitos humanos suscitava reações depreciativas e 
era frequentemente associada pela opinião pública à defesa dos direitos de bandidos, à utopia de militantes que imaginavam uma sociedade livre da violência ou à sede de vingança por parte de quem havia sido perseguido pela ditadura militar.

Maria Victória Benevides (1983) fez um estudo sobre a violência urbana no noticiário de imprensa e constatou que o levantamento de opiniões de representantes oficiais apresentava, em 1983, em média, o seguinte padrão: discussão sobre as causas socioeconômicas; responsabilidade da polícia, omissa, despreparada e sem recurso; disposições inatas do criminoso; e responsabilidade da própria sociedade, passiva e negligente. As soluções pensadas podem ser diferenciadas em dois grandes grupos: os que se preocupam prioritariamente com segurança e justiça e defendem mudanças estruturais (como mudanças estruturais na polícia, de descentralização, policiamento preventivo nos bairros) e aqueles mais preocupados com segurança e repressão, que optam pelo aumento do policiamento ostensivo e fardado e pelo maior rigor nas penalidades. O ponto é que essa visão de uma sociedade ao mesmo tempo culpada e absolvida - o que acontece ainda nos dias de hoje, segundo a autora, é que alimenta a lógica de insegurança diante da incompetência, da omissão e da impotência das autoridades supostamente competentes, aproximando-se da visão de desordem. (BENEVIDES, 1983)

Mas em 1988 veio a Constituição instituindo o Estado democrático de direito e contemplando os direitos humanos, bem como uma série de meios para sua proteção e garantia, incorporando-os no direito positivo pátrio, fazendo com que deixem de ser apenas princípios filosóficos. Pelo novo texto, ao Estado ficou atrelada a responsabilidade da consolidação de uma cidadania democrática, que só é possível a partir da concretização dos direitos humanos.

É certo que a partir de 1985, e mais claramente na década de 1990, teve início um processo de diálogo entre o governo federal e organizações não-governamentais na busca de soluções para o problema da criminalidade violenta e da impunidade nos grandes centros urbanos do país. (MESQUITA NETO, 2010) Mas é especialmente nos últimos anos que os direitos humanos têm adquirido projeção no cenário nacional, e uma abordagem cada vez mais diferenciada, principalmente em razão dos Programas Nacionais de Direitos Humanos, que oficializaram a preocupação com os direitos humanos na agenda governamental, a partir de um diálogo e a cooperação entre governo e sociedade civil. 
Apesar a Constituição Federal prever a segurança como um direito fundamental, conforme os artigos $6^{\circ}$ e $144,{ }^{2}$ a concretização desse direito ainda é muito retórica.

O artigo III da Declaração Universal dos Direitos Humanos de 1948 prevê que "toda pessoa tem direito à vida, à liberdade e à segurança pessoal." A diretriz da Organização das Nações Unidas pode ser entendida em sentido amplo, sugerindo que não só a segurança individual deve ser respeitada, mas também os bens imateriais que são caros ao ser humano, como o talento, os esforços, atendimento e amparo em caso de doença etc. Nesse sentido, o direito à segurança é um esforço a ser feito pelas instituições públicas para que a vida e a liberdade sejam preservadas e protegidas. (SCHILLING, 2009)

Problemas nesse campo foram surgindo no Brasil de forma cada vez mais diversa e complexa. A necessidade de se buscar a concretização da cidadania e a implementação dos direitos fundamentais foi um dos motivos pelos quais foi apresentado o PNDH-1, fazendo com que, de certa forma, a segurança pública passasse a ocupar lugar diferenciado na pauta de preocupações do governo, em parceria com a sociedade.

De fato, no momento da elaboração do PNDH-1 (1996) uma das maiores preocupações era o setor da segurança pública, de forma alinhada com os dizeres da Constituição Federal e de documentos internacionais de direitos humanos. O programa trazia propostas de ação para algumas das inquietações mais sérias no campo da segurança, como corrupção, crime organizado, tortura, tráfico de drogas e outras violações à lei e aos direitos humanos e abarcou uma série de recomendações, a partir de ampla consulta à sociedade civil, que participou por meio de sugestões e críticas em debates e seminários, com vistas, principalmente, a estancar a banalização da morte, obstar a perseguição e a discriminação contra os cidadãos e tornar a Justiça mais eficiente, de modo a assegurar de forma mais efetiva o acesso da população ao Judiciário e o combate à impunidade. (BRASIL, 1996)

Em 2002 foi lançado o PNDH-2, em complementação ao PNDH-1, incorporando ações específicas no campo da garantia do direito à educação, à saúde, à

\footnotetext{
${ }^{2} \mathrm{O}$ artigo $6^{\circ}$ diz que direito à segurança "implica desenvolver políticas públicas de segurança que garantam os direitos de todos, como educação, saúde e dignidade, sem discriminação e respeitando as diferenças." (MATSUDA; et. al., 2009, p. 33); já o artigo 144 diz que a segurança pública é dever do Estado, direito e responsabilidade de todos, mostrando a importância do papel da intervenção estatal no setor, por meio de políticas públicas, que visem preservar a ordem pública, a incolumidade das pessoas e a integridade do patrimônio (MATSUDA; et. al., 2009), bem como do papel de cada cidadão, em consonância com o modelo democrático adotado.
} 
previdência social e assistência social, ao trabalho, à moradia, a um meio ambiente saudável, à alimentação, à cultura e ao lazer. (BARAZAL, 2010) As propostas governamentais desse plano também demonstram preocupação com o setor da segurança. Duas das ações previstas eram: o apoio à execução do Plano Nacional de Segurança Pública - PNSP e o incentivo à formação de policiais em direitos humanos.

Em meados dos anos 90 o desenvolvimento econômico e social e a transição para democracia, embora evidentes e necessários, não eram suficientes para conter o aumento da criminalidade e da violência no Brasil. A questão que se colocava era se a tendência de banalização da criminalidade, da violência e da morte poderia ser controlada e revertida, ou se acabaria por consumir os recursos humanos da sociedade brasileira a ponto de inviabilizar os processos de desenvolvimento e de consolidação da democracia no país. (PINHEIRO; MESQUITA NETO, 1997)

Não é errado afirmar que desde o lançamento do primeiro Programa houve diminuição da tolerância com relação à impunidade e às violações de direitos humanos no país, com a participação mais incisiva do governo federal, que "passou a exercer papel ativo na proteção e promoção dos direitos humanos, criando condições menos favoráveis para a continuidade de práticas ilegais e violentas na resolução de conflitos". (PINHEIRO; MESQUITA NETO, 1997)

O que acontece é que o primeiro PNDH limitou sua atuação aos direitos civis. Somente com o segundo programa foram incluídos os direitos sociais, econômicos e culturais. Se a segurança não é "simplesmente uma questão de polícia, mas uma questão social, qualquer programa que se limite somente ao aspecto policial ou judiciário da questão será sempre parcial e falho." (TOSI, 2002, p. 242) Mesmo assim, o paradigma de que a violência é consequência de fatores sociais não consegue mais dar conta do fenômeno criminoso, como queria o Plano Nacional de Segurança Pública - PNSP de 2000. (FIA, 2010) O debate da segurança pública hoje compreende questões mais complexas, nuances que vão além do discurso de direita e esquerda sobre repressão ou prevenção.

Os dois primeiros planos constituíram, sem dúvida, um avanço para a democracia e a consolidação dos direitos humanos, mas o governo federal sentiu a necessidade de aprofundar e ampliar o elenco de direitos, considerando as demandas nascidas de cinquenta conferências temáticas realizadas desde 2003. O PNDH-3, hoje em vigor, é bem mais extenso e apresenta organização distinta. (ADORNO, 2010) 
Segundo Adorno (2010), o programa atual incorpora uma nova concepção de direitos humanos, reconhecendo sua indivisibilidade: "direitos humanos não são apenas direitos civis e políticos, mas também direitos econômicos, sociais, culturais e coletivos, o que é uma grande novidade na história social e política republicana no Brasil.”

Não só os PNDHs merecem destaque, mas também outras iniciativas do governo são louváveis nessa grande área dos direitos humanos e sua relação com a segurança pública, como o Programa Nacional de Segurança Pública com Cidadania PRONASCI, do Ministério da Justiça, que se presta a articular políticas de segurança com ações sociais, envolvendo os diversos atores, atuando de forma preventiva.

Considerando todas essas (e tantas outras) ações, é importante fazer um balanço para tentar entender algumas questões que se colocam como o andamento das decisões e do planejamento para ações futuras de conscientização em direitos humanos na área da segurança.

Nos dias de hoje, o que se busca é um sistema único de segurança, com a reestruturação das polícias, o incentivo e a implementação de políticas públicas, que envolvam governo, organizações não-governamentais e comunidade, "mais amplas e complexas do que as iniciativas possíveis às chamadas 'forças da segurança', o surgimento de nova geração de policiais, disposta a repensar práticas e dogmas." (BRASIL, 2009)

Não obstante os avanços, a segurança ainda é um campo problemático, além de ser objeto constante de exploração da mídia. A questão é delicada por alguns motivos. Em primeiro lugar, podemos pensar na criminalidade - presente nos grandes centros urbanos, vista como grande problema, em razão dos mais diversos e complexos fatores: o grande crescimento de cidades, a falta de planejamento urbano, a desigualdade social, as hesitações sobre políticas mais consistentes nas áreas da educação e da saúde, entre outros - e no medo da criminalidade. ${ }^{3}$ Por outro lado, não se pode descartar que ainda existe certa resistência em se pensar em direitos humanos - o que é muito complicado se considerarmos um Estado que tem como fundamento a dignidade da pessoa humana.

\footnotetext{
${ }^{3}$ É importante atentar para o fato de que criminalidade e medo da criminalidade são coisas distintas. Fernando Salla (2006), em artigo dedicado ao tema dos ataques do PCC ocorridos no ano de 2006, releva o medo da criminalidade é maior do que a insegurança real: "Pesquisa produzida pelo jornal $O$ Estado de S. Paulo e pelo IBOPE (divulgada em 29/08/2006) mostrou que $26 \%$ da população de São Paulo alteraram sua rotina de vida em função dos ataques do PCC. Mas, o mais curioso é que em todas as regiões do Brasil essas porcentagens (que variavam de 19 a $28 \%$ ) praticamente se repetiram, ainda que os ataques tenham ocorrido quase que exclusivamente no Estado de São Paulo. Ou seja, o medo se alastrou por diversos Estados brasileiros, talvez como efeito muito mais da divulgação dos acontecimentos pela mídia do que em função das reais condições de insegurança urbana nas cidades."
} 
Desde o primeiro PNDH estão entre as maiores preocupações a falta de segurança das pessoas e o aumento da violência. O Programa de 2009 contém uma série de orientações significativas na área da segurança pública, que exigem um esforço conjunto do governo com a sociedade para a preservação da vida e da liberdade humana. Mas é certo também que o Brasil ainda é um país com alto índice de violência, em especial nos grandes pólos urbanos.

A intenção explícita no PNDH-3 e nos documentos sobre segurança pública existentes é a de integração. Obviamente, a ideia ainda é muito recente e embrionária, necessita de muito tempo, empenho político, social, individual, mas a concepção é inédita, de diálogo, integração e cooperação. A segurança não é mais tão-somente uma questão de polícia, é, antes, uma questão social - que compreende a vida, a liberdade, a saúde, o trabalho, a moradia, a educação -, e antes no sentido cronológico, tendo a polícia como um personagem fundamental para garantir que não haja o uso da repressão sem necessidade.

O problema da segurança no Brasil, portanto, não pode mais estar apenas adstrito ao repertório tradicional do direito e das instituições da justiça, particularmente, da justiça criminal, presídios e polícia, como observa o Observatório de Segurança Pública (2011).

A situação atual mostra que as soluções devem passar pelo fortalecimento do Estado na capacidade em gerir a violência, de apresentar e gerir políticas públicas de segurança, e pelo alongamento dos pontos de contato das instituições públicas com a sociedade civil e com a Universidade. Os gestores da segurança pública devem enfrentar esses desafios e fazer com que o debate sobre o tema transforme-se em real controle sobre as políticas de segurança pública e estimule a parceria entre órgãos do poder público e sociedade civil, numa tentativa de ampliar a sensibilidade de todo o sistema da segurança a "novas idéias e energias provenientes da sociedade e de criar um novo referencial que veja na segurança espaço importante para a consolidação democrática e para o exercício de um controle social da segurança." (OBSERVATÓRIO, 2011)

Políticas públicas, na área de direitos humanos com foco na segurança pública, poderiam ser realizadas para a melhora desse quadro e um esforço nesse sentido já está sendo percebido; no entanto, ainda faltam vontade e capacidade política, social e técnica 
para desenvolver políticas de direitos humanos, o que, certamente, contribui para um déficit de democracia.

A articulação entre o governo, as organizações não-governamentais de direitos humanos e a sociedade, contudo, ainda é pouca. Quando ocorre o diálogo entre as instituições, projetos são desenvolvidos, mas seus resultados se perdem na troca de mandatos, pelo decorrer do tempo ou pela falta de pessoal capacitado para analisar e processar as informações de modo a aproveitá-las na prática.

O Conselho Nacional de Segurança Pública - CONASP é um dos órgãos que se presta a isso - unir governo e sociedade civil na tentativa de conseguir melhores diagnósticos e resultados nas demandas públicas. No ano de 2011, com exceção do Viva Rio, não muitos órgãos atuaram no sentido de trabalhar a questão da segurança pública. Esses órgãos existem para demandar do governo e como muitos membros são do próprio governo instala-se o conflito e o espaço que deveria ter um balanço positivo para a participação popular, em integração com Estado, acaba servindo como campo de desentendimentos e discussões.

Apesar de existirem iniciativas, elas são, muitas vezes, isoladas. A sociedade civil precisa participar de ações, iniciativas, que busquem tocar, através da educação em direitos humanos, o sentido de parceria, de comunidade, de conjunto e da necessidade da participação ativa.

Fernando Salla (2006) compartilha desse entendimento e diz que a questão da segurança pública é muito complexa para ficar restrita aos órgãos governamentais, mas a desarticulação dos órgãos de segurança pública e o pouco diálogo com a sociedade civil indicam que há muito por fazer para superar a crise nesse setor no Brasil.

Essa questão é de grande relevância, pois faz com que se desenvolva na sociedade o problema do medo, não só com relação à criminalidade, mas também em outros sentidos, conforme apresentado por Bauman (2008). Segundo ele, a existência do medo é tão presente que chega a ser bizarro nosso sentimento de alívio quando confrontamos o perigo real, porque ele é factível, sabemos de onde vem e o que precisamos fazer para afastá-lo (2008).

Bauman (2008) afirma que a insegurança e a incerteza nascem do sentimento de impotência, de não estar mais no controle da situação, individual ou coletivamente, do que acontece na comunidade; da mesma forma não estar no controle dos assuntos do 
planeta (quem é capaz de evitar uma guerra se a maior potência política do mundo a quer?).

Maria Victoria Benevides (1983, p. 19) diz que a perplexidade do leitor de jornais da grande imprensa vai se transformando em sentimentos de insegurança e medo: "Trata-se da síndrome causada pela divulgação maciça, em todos os meios de comunicação, do que se convencionou chamar de "onda da violência"”.

Ainda para a autora, a propaganda e o medo crescem mais do que a própria violência, de forma que o que não se pode é confundir a visibilidade de um fenômeno com a sua existência real. (BENEVIDES, 1983)

Para La Haye (2007, p. 95),

\begin{abstract}
Somos aí projetados aos grandes medos do espaço humano tal como o ano 1000, o fim do mundo, a lepra, a peste, o câncer ou a AIDS. E é aí que importa descobrir o que se passa quando somos confrontados àquele que é tão diferente. As causas reais já não bastam. Não se trata apenas do medo da diferença, da violência ou da agressão. Mergulhamos no abismo do fantasma e do imaginário. A serenidade, a aceitação, a abertura, a tomada de consciência, o acesso ao outro e ao simbólico são perdidos. É o universo lúgubre do encerramento, dos sobressaltos e das convulsões, ante os tormentos da morte psíquica.
\end{abstract}

O policial é um dos atores da segurança pública e seu papel é muito relevante na realização do binômio segurança pública x direitos humanos; contudo, é justamente essa instituição que encontra maior resistência na aceitação do novo paradigma.

A desconfiança, a falta de amizade, de estima, de satisfação e o temor da população com relação aos policiais, cujo perfil é o de um agente corrupto e violento, vem não só da atitude de algumas figuras descompromissadas com a lei e com o ser humano, mas também da intensa propaganda negativa e do medo.

Benevides (1983, p. 74) percebeu isso em seu estudo e ilustrou com algumas falas que colheu durante a pesquisa: "Quando a polícia passa com a viatura as pessoas mudam o comportamento; ninguém conversa, todo mundo muda de assunto, se afasta, o ambiente fica tenso."

Ademais, a exclusão é um fator muito importante e que merece ser considerado.

Segundo a Organização das Nações Unidas, todos nascem livres e iguais em dignidade e direitos, porém essa idéia de universalidade não é fácil. Constroem-se figuras do outro, que não pertenceria à categoria do humano por motivos de raça, convicção religiosa, orientação sexual etc. Nesse sentido, o direito à vida, à liberdade e à segurança fica comprometido. A isso se agregam as questões contemporâneas de uma sociedade de consumo, onde quem não tem, não é, não pertence. A cultura do consumo 
se reflete nos assassinatos e na criminalidade urbana. Se a vida não tem valor, a morte se torna banal; liberdade e segurança dependem da capacidade de cuidar do direito à vida. (SCHILLING, 2009)

A desigualdade é um fator gerador de violência quando aliada a questões culturais, à necessidade de integração na sociedade do consumo. (MATSUDA, 2009)

Quem atribui o envolvimento com o crime a necessidades econômicas
freqüentemente esquece o papel que a cultura, os valores, a normas sociais e
os símbolos desempenham. A autoestima é tão importante para a
sobrevivência humana quanto um prato de comida (SOARES, 2009, p. 44)

Uma das conseqüências da ambigüidade da associação criminalidade / pobreza é que "uma vez que os pobres são, automaticamente, 'os principais suspeitos', justificamse os procedimentos violentos e arbitrários da polícia." A estigmatização faz com que polícia, imprensa e população incorporem e apóiem ostensivamente a ação brutal nas batidas em favelas, em bairros pobres, prisões ilegais etc. (BENEVIDES, 1983, p. 50) A entrevista de um delegado do Rio sobre uma batida na favela em 1979 revelou: "É claro que eles ficam marcados definitivamente, e na próxima batida já serão considerados com antecedentes. E enquanto não descobre, a polícia fabrica suspeitos”. (BENEVIDES, 1983, p. 51)

No Brasil, o papel da polícia - dentro da grande temática da segurança pública é um dos mais explorados nesse debate, atraindo o interesse acadêmico e de ONGs e continua sendo um dos mais neurálgicos nos tempos atuais: estuda-se a letalidade policial, a tortura, as estruturas de organização policial, a relação com a população, como deveria ser o desempenho de suas funções, quais são essas funções.

Os problemas que circundam a realidade do policial brasileiro certamente são grandes responsáveis por essa situação. A polícia carece de investimento em todos os seus setores: financeiro, de estrutura e de formação. Com efeito, "as agências policiais (...) recrutam seus operadores nas mesmas camadas sociais com maior incidência das seleções criminalizante e vitimizante." Ademais, os equipamentos que são fornecidos aos policiais não atendem à necessidade operacional, sofrendo uma defasagem tecnológica em relação ao poder de fogo da criminalidade. Esses gastos acabam saldados com arrecadações ilícitas que os operadores efetuam, suprindo o orçamento estatal, criando um paradoxo: a agência de prevenção do delito se financia pela prática de alguns delitos, gerando uma deterioração ética e de autoestima (ZAFFARONI; et al., 2003, p. 56). Finalmente, a educação dos policiais em direitos humanos é precária. A 
deficiência de formação do policial é tão séria quanto a falta de estrutura material e ao ignorar esse aspecto o Brasil deixa de formar agentes de transformação social e política.

Apesar dos enormes avanços na área dos direitos humanos, tanto no âmbito nacional quanto no estadual, São Paulo ainda é palco de muitos acontecimentos que preocupam a comunidade e o governo. ${ }^{4}$ Muito se discute sobre o binômio polícia civil $\mathrm{x}$ direitos humanos, mas a exploração do tema é mais midiática ou pontual (principalmente pelo trabalho de organizações não-governamentais, que produzem relatórios, cartilhas e outros textos, ou por algumas revistas especializadas). ${ }^{5}$

Durante o período de exceção a polícia civil se utilizou de métodos violentos para manter a ordem pública e garantir a segurança nacional, extraindo confissões sob tortura, efetuando prisões arbitrárias, conforme diversos relatos que hoje estão publicados. ${ }^{6}$ Não bastasse a imagem negativa desse período, a atuação da polícia civil tem sido manchada pelo trabalho corrupto e violento de muitos policiais, que são os que aparecem nas páginas de jornais e revistas, provocando repulsa à figura do policial e criando um perfil difícil de ser modificado. ${ }^{7}$

Além disso, o acesso a informações junto à polícia civil sempre foi mais difícil, o que também é herança do período ditatorial. A organização sempre foi conhecida por ser extremamente corporativa. Por conta disso, o interesse na formação do policial civil em direitos humanos sequer tem espaço, sendo raros os estudos específicos sobre o tema no Brasil.

Em regra, a resistência aos direitos humanos é tão presente nas instituições policiais que gera dificuldades de implementação de políticas públicas que tenham por objetivo desenvolver um trabalho de conscientização do policial para pôr em prática os direitos do homem.

\footnotetext{
${ }^{4}$ Outros Estados brasileiros, como o Rio de Janeiro, por exemplo, enfrentam problemas seríssimos nessa área. A violência policial no Rio é tão gritante que tem sido explorada, inclusive, pelo cinema nacional. Um dos últimos filmes produzidos sobre o assunto é o Tropa de Elite 2, que tem como protagonista "o primeiro super-herói brasileiro", o Capitão Nascimento, que é "violentamente honesto" e "incorruptível, implacável com bandidos e espanca políticos degenerados", de acordo com a capa da Revista Veja que contém matéria sobre o filme (2010).

${ }^{5}$ Guaracy Mingardi (1992, p. 2) aponta isso em sua pesquisa sobre a polícia civil. O autor, que estudou o que deve fazer a polícia, o combate ao comportamento tipificado por lei como criminoso e a maneira pela qual a polícia cumpre sua função, acredita que muitos se preocupam com a segurança pública e o aumento da criminalidade, mas poucos se detêm ao estudo do ator (e não da platéia).

${ }^{6} \mathrm{Um}$ dos livros que traz interessante colação de relatos sobre a época da ditadura militar no Brasil é Direito à Memória e à Verdade da Secretaria Especial dos Direitos Humanos da Presidência da República.

${ }^{7}$ Sobre a atuação da polícia, brilhante o trabalho de Guaracy Mingardi, no livro Tiras, Gansos e Trutas, da Editora Página Aberta.
} 
A boa notícia é que o perfil da instituição policial civil tem sido modificado nos últimos anos, por iniciativa de membros da própria instituição, como se verifica, por exemplo, na Academia de Polícia paulista Dr. Coriolano Nogueira Cobra, que possui o Centro de Direitos Humanos e Segurança Pública Dr. Celso Vilhena Vieira, do qual fazem parte Delegados de Polícia que são professores da casa e se preocupam com a educação e a conscientização do alunado da ACADEPOL em direitos humanos. Eles se reúnem semanalmente para tratar de questões que circundam a formação do policial e desenvolvem atividades que refletem nos conteúdos programáticos da disciplina direitos humanos dos cursos dados na Academia - de formação e de aperfeiçoamento -, promovem seminários, debates, pesquisas, grupos de estudos e outras atividades educativas na área de direitos humanos e segurança pública. (SÃO PAULO, 2006)

Umas das atividades mais recentes do CDHSP, em parceria com a Universidade Zumbi dos Palmares, foi a promoção de um encontro em que policiais civis negros foram convidados a palestrar para os alunos da ACADEPOL sobre temas como a diferença, a diversidade, a desigualdade. ${ }^{8}$

Nos últimos anos, a polícia civil do Estado de São Paulo tem se mostrado empenhada em modificar a imagem negativa e tem desenvolvido atividades que são interessantes, pois demonstram que algumas mudanças internas têm ocorrido e provocado uma alteração na representação do perfil do policial que se desejaria ter numa democracia. Alguns exemplos são o Núcleo Especial Criminal - NECRIM, um núcleo que funciona em Lins, interior de São Paulo, em que se estimula a conciliação como solução de conflitos, por intermédio de policiais, como uma verdadeira iniciativa de policiamento comunitário da polícia civil; o Projeto ACADEPOL Cidadã, que estimula o diálogo entre polícia e sociedade; e outros eventos de aproximação com a comunidade (como o ocorrido em 2010 com moradores de rua), entre outros.

O Programa Estadual de Direitos Humanos do Estado de São Paulo, de 1997, que surgiu também em decorrência do Programa Nacional de Direitos Humanos, prevê algumas medidas relativas à segurança pública, inclusive com relação à formação do policial civil em direitos humanos. Mas muitas questões surgem a partir do Programa Estadual, tais como: até que ponto essas medidas foram ou estão sendo colocadas em

8 Para maiores informações consultar a página da internet: <http://www2.policiacivil.sp.gov.br/x2016/modules/news/article.php?storyid=2233>. Acesso em: 25 nov. 2011. 
prática? Qual a efetividade dessas medidas? Qual o apoio efetivo que a polícia civil de São Paulo recebe (do governo e da sociedade) para formar em direitos humanos?

É fato que a polícia é muito mais temida do que conhecida pela ciência política (PAIXÃO, 1992), no entanto não se pode negar que ainda resta muito da cultura de exceção. Os vinte e um anos de ditadura militar no Brasil contribuíram para que dentro da instituição policial se formasse um pensamento conservador, autoritário, patriarcal, hierarquizado e fechado. Por conta disso, dos reflexos dessa cultura, a atuação da polícia ainda tem sido muito marcada pelo uso excessivo da força.

Bittar (2009, p. 218-219) lembra, contudo, que "o Brasil é um país que se ergue sobre um processo de modernização incompleto, cujas consequências têm sido lentamente percebidas e vividas pela sociedade." Aqui se vive, ao mesmo tempo, a prémodernidade, a modernidade e a pós-modernidade. Dessa forma, é complicado se falar em homogeneidade na condução das políticas públicas, na aplicação da legislação e no desenvolvimento de atividades sociais no Brasil.

Diante disso, aproveitando a abertura e o incentivo que a instituição policial tem dado às pesquisas na área de direitos humanos, o apoio do Centro de Direitos Humanos Dr. Celso Vilhena Vieira, e o acesso às informações para o desenvolvimento da pesquisa, é que foi possível desenvolver este estudo. A análise está centrada na polícia civil e nos trabalhos de educação do policial em direitos humanos realizados pela ACADEPOL para os cursos de formação.

O objetivo principal foi entender um braço dessa formação em direitos humanos no atual contexto democrático em uma das instituições mais difíceis de se deixar permear por esse discurso, identificando algumas ações e suas limitações. Além disso, tratou-se de identificar ações existentes, por iniciativa da própria polícia, e que integram esse trabalho de formiguinha que é a formação em direitos humanos do policial civil de São Paulo.

O que se quis foi fazer um diagnóstico da forma como a polícia civil de São Paulo ensina direitos humanos aos recém-chegados na instituição, identificando pontos positivos e negativos, destacando potencialidades, limites e desafios, a partir da análise dos conteúdos programáticos da disciplina direitos humanos dos cursos de formação das carreiras e de algumas falas de pessoas que participam dessa formação.

O arcabouço teórico sobre polícia, segurança pública e direitos humanos, junto com a análise do conteúdo programático da disciplina direitos humanos dos cursos de 
formação das carreiras da polícia civil do Estado de São Paulo e com as entrevistas realizadas permitiram pensar a formação em direitos humanos dos policiais civis dentro do contexto sócio-econômico-político-cultural de São Paulo, tornando possível, ainda, arriscar alguns apontamentos que possam, talvez, contribuir para o aprimoramento da segurança pública, permitindo algum tipo de operacionalização prática a partir da perspectiva teórica resultante da pesquisa. 


\section{CONSIDERAÇÕES FINAIS}

O presente trabalho buscou contribuir para a resposta da seguinte indagação: como se dá a formação em direitos humanos dos policiais civis do Estado de São Paulo?

O objetivo central era entender um braço dessa formação no atual contexto democrático em uma das instituições mais difíceis de se deixar permear pelo discurso humanista, identificando algumas ações existentes, de iniciativa de membros da própria polícia, cujas intenções parecem caminhar no sentido de transformar a cultura do policial civil paulista, e algumas das limitações não só para essas ações mas para qualquer transformação da instituição nesse sentido.

Conforme alertado desde o início, a investigação não teve o condão de detectar efeitos porventura gerados com essa formação, mas apenas entender como acontece o processo de educação em direitos humanos na polícia civil de São Paulo e sentir se isso incomoda, inova ou cria novas possibilidades de atuação no cotidiano desses agentes.

A Academia de Polícia Civil de São Paulo é o espaço para onde vão todos os aprovados nos concursos para as carreiras policiais civis do Estado. Existem alguns núcleos de estudos, unidades no interior, todos ligados à Academia Dr. Coriolano Nogueira Cobra, Departamento que responde pelo processo de formação dos policiais civis.

A linda de ensino da polícia civil paulista parece bastante técnica, conforme os conteúdos programáticos analisados e alguns relatos dos policiais entrevistados. A polícia judiciária, cujo trabalho consiste basicamente na investigação de crimes para que o Judiciário consiga, a partir dos dados fornecidos, processar e julgar suspeitos nos limites da lei, procura capacitar seus agentes para que consigam conduzir o trabalho de forma eficiente.

O tempo que o aluno passa nas salas de aula da ACADEPOL costuma ser dedicado a matérias como armamento e tiro, condicionamento físico, investigação policial, criminalística, gerenciamento de crise, defesa pessoal, estágio, entre outras, e menos a disciplinas como ética, direitos humanos, criminologia e policiamento comunitário. A filosofia humanista, por não ser uma linha de pensamento e trabalho dentro da instituição, dificilmente entra nas discussões que dizem respeito à atividade policial, dependendo muito mais de pessoas que acreditam e praticam essa forma de 
vivência e que levam, da maneira como podem, para suas aulas a relação do tema com a rotina na profissão e com a vida do policial.

O discurso oficial da polícia civil, a favor dos direitos humanos, mostra-se um pouco retórico. A existência de uma disciplina sobre os direitos da pessoa se deve a dois grandes motivos.

O primeiro deles é a pressão política, especialmente nos anos 90, após o desgaste do policial e dos agentes de segurança em geral no âmbito nacional e internacional com o episódio do Carandiru e com outros tantos, em geral os ainda ligados à forma de ser da polícia no regime de exceção. A cobrança externa por uma posição do país com relação a mudanças e respeito aos direitos humanos, e a movimentação interna, especialmente com o Programa Nacional de Direitos Humanos, fizeram com que a instituição policial civil se abrisse à possibilidade de investir na formação de seus agentes no sentido de provocar uma transformação cultural.

Os três Programas federais de direitos humanos e os demais que foram surgindo em decorrência deles foram importantes documentos na afirmação da democracia no país. A formação da polícia está prevista como uma das medidas necessárias para que se melhore o quadro da segurança, tão complexo e caótico no Brasil. A integração, o diálogo e a tolerância são características que esses instrumentos buscam e algumas ações foram exigidas do governo estadual e da polícia paulista. Por isso, a conveniência e a oportunidade políticas, o momento de abertura para iniciativas de afirmação democrática e de direitos humanos.

O segundo motivo é a coragem e a ousadia de um policial, cuja experiência de vida foi de solidariedade e respeito à vida e à liberdade, que, ocupando o cargo de direção da Academia, conseguiu (pela oportunidade surgida em razão do momento político) inserir na grade curricular uma disciplina chamada direitos da cidadania e implementar uma série de atividades absolutamente inovadoras e que buscavam tocar os sentimentos dos policiais e despertar neles o entendimento e a vivência dos direitos humanos. Essas atividades aconteceram por um período curto de tempo, pois os contrários à filosofia humanista, por força de pessoas influentes que acreditam que esse tipo de intervenção prejudica a eficiência policial. Contudo, a disciplina sobre direitos humanos permaneceu, junto com um grupo de estudos dedicado ao tema, também fundado por esse diretor, numa relação de apoio mútuo. De fato, o Centro de Direitos Humanos e Segurança Pública, fundado no mesmo ano em que a disciplina sobre 
direitos humanos integrou a grade da ACADEPOL, é um espaço de reunião de pessoas interessadas e preocupadas com a transformação cultural da polícia civil. Quase todos delegados de polícia, esses membros também são docentes na Academia e buscam nas reuniões o apoio e a troca de ideia com os colegas com quem têm afinidade para conseguirem desenvolver seus trabalhos da forma mais positiva possível, ou seja, de forma que seus esforços produzam efeitos maiores, resultados práticos.

A disciplina atualmente tem 16 horas / aulas e abarca discussões sobre direitos humanos em geral e sobre diversidade étnico racial.

A questão da diferença e da tolerância entrou no programa especialmente por conta do trabalho dos membros do CDHSP em eventos, seminários, publicações e outras inciativas. A carga horária é baixa e o conteúdo, muitas vezes, é tratado de forma marginal pelos docentes da Academia, salvo aqueles que buscam mostrar aos alunos as relações entre suas disciplinas e os direitos humanos, ou seja, depende muito de cada professores, da subjetividade de cada um, trabalhar o tema de forma transversal.

As poucas horas dedicadas ao tema inviabilizam propostas que poderiam enriquecer o aprendizado como levar os alunos para fora da sala de aula em atividades de campo para sensibilização ou mesmo palestras de pessoas não pertencentes à polícia, como assistentes sociais, filósofos, antropólogos, sociólogos. Além disso, da baixa carga horária de direitos humanos e disciplinas correlatas, por vezes, os cursos de formação são mais rápidos, mais enxutos, prejudicando os espaços de reflexão em prol daqueles que dão capacitação técnica suficiente para colocar o profissional em campo em razão da forte demanda, da exigência de mais policiais em um curto período de tempo.

Com isso, não se pode dizer que a formação do policial civil de São Paulo é ruim. Está aquém do que poderia ser, porém, há questões bastante positivas e que merecem ser destacadas.

Com os Programas de direitos humanos - PNDHs, Programa Estadual, PRONASCI e outros - o Brasil e o Estado de São Paulo se comprometeram com a questão e com sua relação com a segurança pública. A preocupação, pela primeira vez, agora faz parte da agenda governamental. Com isso, os Estados são cobrados no sentido de tomarem iniciativas condizentes com um Estado Democrático de Direito, juntamente com organizações não-governamentais e com a comunidade. Essa preocupação, essas cobranças e a necessidade de implementar ações, mesmo que ainda sejam muito 
retóricas e de pouco alcance prático, consistem em medidas inovadoras, uma evolução rumo à consolidação democrática e dos direitos humanos no país.

Outro ponto positivo é a abertura para polícia para ações que tocam a questão dos direitos humanos. Mesmo que a cultura da exceção, da segurança nacional, da ordem e do progresso ainda esteja arraigada na instituição policial civil paulista, é fato que pessoas de dentro, com experiências de vida e discernimento que possibilitem uma transformação cultural, conseguem trabalhar e produzir resultados otimistas no campo da formação em direitos humanos.

Iniciativas boas na polícia existem e se transformam em práticas, como ficou demonstrado a partir de alguns exemplos de condução de trabalhos no exercício das funções organizacionais das pessoas entrevistadas. Mas também ocorrem no campo da formação, na disseminação da cultura humanista, como nos casos dos projetos mencionados ao longo do trabalho, de que é exemplo o Academia de Polícia cidadã.

Essas e outras ações demonstram que a polícia civil paulista tem forte potencial para desenvolver uma formação cada vez mais humanizada. Tanto é que a Academia de São Paulo é uma das mais avançadas nesse sentido, pioneira na implementação dos direitos humanos e lugar de experiências sequer vividas por policiais em outros Estados. Mas essas práticas, essas iniciativas e ações encontram sempre pontos de atrito com a cultura verticalista e patriarcal da polícia, com a influência dos longos anos de ditadura militar, com a resistência com relação a quaisquer tipos de mudança.

O grande desafio consiste na quebra de um paradigma ético, por meio da reestruturação da polícia através de alteração constitucional que vise integração. Fazer com que isso aconteça é algo quase utópico considerando o contexto sócio-econômicopolítico-cultural. As mais importantes dificuldades estão no tratamento que a polícia recebe do próprio Estado: salários, condições de trabalho etc.

Contudo, algumas ações podem ser tomadas no sentido de uma transformação cultural, são factíveis e auxiliam no aprimoramento da segurança pública, na construção de políticas públicas. A operacionalização desse tipo de prática, com o tempo, viabiliza melhoras na contenção da criminalidade a partir do incentivo à formação em direitos humanos, do surgimento de uma nova geração de policiais que trabalhem para transformação de alguns agentes e do envolvimento com a sociedade, tratando a segurança pública como um problema social. 
A formação em direitos humanos do policial civil de São Paulo, portanto, é uma medida importante na afirmação da democracia e do respeito aos direitos fundamentais do homem, especialmente a vida, a liberdade e a segurança. Trata-se, porém, de parte de um conjunto, ou seja, a formação desses agentes é apenas um dos elementos que precisam de grandes modificações para que ocorra uma mudança na polícia civil paulista. Questões que envolvem melhores condições de trabalho, estrutura material, de saúde, salários e tantos outros fatores devem ser tratados de forma sistêmica - assim com a segurança pública em relação à educação, à saúde, à moradia etc no país e nos Estados. O sucesso de um depende, em grande medida, do sucesso do outro.

O que não se pode é negligenciar a educação. Medidas mais imediatas são importantes e devem ser tomadas, mas a formação é um dos pilares de sustentação de qualquer mudança, sem o qual as ações realizadas serão perdidas, esvaziadas e sem efeito. 


\section{REFERÊNCIAS BIBLIOGRÁFICAS}

ADORNO, Sérgio. História e desventura: o $3^{\circ}$ Programa Nacional de Direitos Humanos. Novos Estudos - CEBRAP, São Paulo, n. 86, mar. 2010. Disponível em: <http://www.scielo.br/scielo.php?script=sci_arttext\&pid=S0101$33002010000100001 \& l a n g=p t>$. Acesso em: 1 dez. 2010.

AMBOS, Kai. Apresentação à edição em língua espanhola. In: CHOUKR, Fauzi Hassan; AMBOS, Kai (Coords.). Polícia e Estado de Direito na América Latina. Rio de Janeiro: Lumen Juris, 2004. p. ix-xii.

BACILA, Carlos Roberto. Polícia e direitos humanos: incompatibilidade? In: CHOUKR, Fauzi Hassan; AMBOS, Kai (Coords.). Polícia e Estado de Direito na América Latina. Rio de Janeiro: Lumen Juris, 2004. p. 61-91.

BALESTRERI, Ricardo B. Direitos Humanos: Coisa de Polícia. Porto Alegre: Edições CAPEC, 2003.

BARAZAL, Neusa Romero. A versão brasileira dos direitos humanos. Uma reflexão política-antropológica dos PNDHs I e II. Disponível em:

<http://www.dhnet.org.br/dados/pp/edh/barazal_versao_br_dh_pndh_1_2.pdf>.Acesso em: 26 nov. 2010.

BASTOS, Emerson Abreu. A Formação profissional de policiais de investigação criminal (delegados e detetives): Estudo dos Currículos da Academia de Polícia Civil de Minas Gerais de 1985 a 2002. 2008. 106 f. Dissertação (Mestrado em Educação). Faculdade de Educação da Universidade Federal de Minas Gerais. Disponível em: <http://www.bibliotecadigital.ufmg.br/dspace/bitstream/1843/VCSA826QZG/1/1000000752.pdf>. Acesso em: 22 jul. 2011.

BAUMAN, Zygmunt. Medo líquido. Tradução de Carlos Alberto Medeiros. Rio de Janeiro: Jorge Zahar, 2008.

Modernidade e ambivalência. Rio de Janeiro: Jorge Zahar, 1999.

BENEVIDES, Maria Victoria. Educação em Direitos Humanos: de que se trata? Programa Ética e Cidadania: construindo valores na escola e na sociedade. 2007. Disponível em: <http://portal.mec.gov.br/seb/arquivos/pdf/Etica/9_benevides.pdf>. Acesso em 20 jul. 2011.

Violência, Povo e Polícia: Violência Urbana no Noticiário de Imprensa. São Paulo: Brasiliense, 1983.

BENTO, Cláudio Moreira. A Academia Real Militar (A Atual Aman):

Uma Decorrência da Vinda da Família Real para o Brasil em 1808. 28 mai. 2009.

Disponível em: <http://www.ihgrgs.org.br/artigos/academia_militar.htm>. Acesso em: 23 ago. 2010. 
BICUDO, Hélio Pereira. Meu depoimento sobre o esquadrão da morte. 10 ed. São Paulo: Martins Fontes, 2002.

BITTAR, Eduardo C. B. O direito na pós-modernidade. 2. ed. Rio de Janeiro: Forense Universitária, 2009.

BRAGA JÚNIOR, Marcos. O conceito de polícia e a noção de segurança no contexto atual dos direitos humanos. In: BITTAR, Eduardo (Coord.). Direitos humanos no século XXI: cenários de tensão. Rio de Janeiro: Forense Universitária; São Paulo: ANDHEP; Brasília: Secretaria Especial dos Direitos Humanos, 2009. p. 442-458.

BRASIL. Ato Institucional n. 5, de 13 de dezembro de 1968. Presidência da República. Casa Civil. Subchefia para Assuntos Jurídicos. Disponível em: <http://www.planalto.gov.br/ccivil_03/AIT/ait-05-68.htm>. Acesso em: 19 nov. 2010.

Decreto-Lei n. 2.848, de 7 de dezembro de 1940. Institui o Código Penal. Presidência da República. Casa Civil. Subchefia para Assuntos Jurídicos. Disponível em: <http://www.planalto.gov.br/ccivil_03/Decreto-Lei/Del2848compilado.htm>. Acesso em: 19 nov. 2010.

Decreto-Lei n. 3.688, de 3 de outubro de 1941. Institui a Lei das Contravenções Penais. Disponível em: <http://www.planalto.gov.br/ccivil_03/DecretoLei/Del3688.htm>. Acesso em: 19 nov. 2010.

Decreto-Lei n. 3.689, de 3 de outubro de 1941. Institui o Código de Processo Penal. Presidência da República. Casa Civil. Subchefia para Assuntos Jurídicos. Disponível em: <http://www.planalto.gov.br/ccivil_03/Decreto-Lei/Del3689.htm>. Acesso em: 19 nov. 2010.

. Constituição da República dos Estados Unidos do Brasil, de 24 de fevereiro de 1891. Presidência da República. Casa Civil. Subchefia para Assuntos Jurídicos. Disponível em: <http://www.planalto.gov.br/ccivil_03/Constituicao/Constituicao91.htm>. Acesso em: 18 nov. 2010.

Constituição da República dos Estados Unidos do Brasil, de 16 de julho de 1934. Presidência da República. Casa Civil. Subchefia para Assuntos Jurídicos. Disponível em: <http://www.planalto.gov.br/ccivil_03/Constituicao/Constituicao34.htm>. Acesso em: 18 nov. 2010.

Constituição da República Federativa do Brasil de 1967. Presidência da República. Casa Civil. Subchefia para Assuntos Jurídicos. Disponível em: <http://www.planalto.gov.br/ccivil_03/Constituicao/Constituicao67.htm>. Acesso em: 18 nov. 2010.

Constituição da República Federativa do Brasil de 1988. Presidência da República. Casa Civil. Subchefia para Assuntos Jurídicos. Disponível em: <http://www.planalto.gov.br/ccivil_03/Constituicao/Constituicao.htm>. Acesso em: 18 nov. 2010. 
Constituição dos Estados Unidos do Brasil, de 10 de novembro de 1937. Presidência da República. Casa Civil. Subchefia para Assuntos Jurídicos. Disponível em: <http://www.planalto.gov.br/ccivil_03/Constituicao/Constituicao37.htm>. Acesso em: 18 nov. 2010.

Constituição dos Estados Unidos do Brasil, de 18 de setembro de 1946. Presidência da República. Casa Civil. Subchefia para Assuntos Jurídicos. Disponível em: 〈http://www.planalto.gov.br/ccivil_03/Constituicao/Constituicao46.htm>. Acesso em: 18 nov. 2010.

Declaração Universal dos Direitos Humanos, de 10 dez. 1948. Adotada e proclamada pela resolução 217 A (III) da Assembléia Geral das Nações Unidas. Ministério da Justiça. Disponível em: <http://portal.mj.gov.br/sedh/ct/legis_intern/ddh_bib_inter_universal.htm>. Acesso em: 16 dez. 2010.

Lei n. 2.033, de 20 de setembro de 1871. Altera differentes (sic) disposições da Legislação Judiciária. Leis do Império. Presidência da República. Casa Civil. Subchefia para Assuntos Jurídicos. Disponível em: <http://www.planalto.gov.br/ccivil_03/Leis/LIM/LIM2033.htm>. Acesso em: 15 nov. 2010.

Programa Nacional de Direitos Humanos - PNDH I. Decreto n. 1.904 de 13 de maio de 1996. Ministério da Justiça. Disponível em: <http://portal.mj.gov.br/sedh/pndh/pndh1.pdf>. Acesso em: 02 dez. 2010.

Programa Nacional de Direitos Humanos - PNDH II. 2002. Ministério da Justiça. Disponível em: <http://portal.mj.gov.br/sedh/pndh/pndhII/Texto\%20Integral\%20PNDH\%20II.pdf>. Acesso em: 02 dez. 2010.

Programa Nacional de Direitos Humanos - PNDH III. Decreto n. 7.037 de 21 de dezembro de 2009. Ministério da Justiça. Disponível em: <http://portal.mj.gov.br/sedh/pndh3/pndh3.pdf>. Acesso em: 02 dez. 2010.

Secretaria Especial dos Direitos Humanos. Comissão Especial sobre Mortos e Desaparecidos Políticos. Direito à memória e à verdade. Brasília: Secretaria Especial dos Direitos Humanos da Presidência da República, 2007.

CANO, Ignacio. Controle de polícia no Brasil. 2006. Disponível em: <http://www.soudapaz.org/Portals/0/Downloads/textocanoppc.pdf>. Acesso em: 21 ago. 2011.

CARDOSO FILHO, Jair Cunha. Avaliação de resultados de uma ação do Pronasci no âmbito do Distrito Federal. 2010. Disponível em: $<$ http://www2.camara.gov.br/responsabilidade-social/edulegislativa/educacaolegislativa-1/posgraduacao/publicacoes/banco-de-projetos/curso-lpp/lpp-1aedicao/proj_jair_cardoso_lpp>. Acesso em: 03 jan. 2012. 
CASTRO, Gabriel. Brasil tem taxa de homicídios maior que a do Afeganistão. Veja on line. 14 dez. 2011. Disponível em: <http://veja.abril.com.br/noticia/brasil/brasil-temtaxa-de-homicidios-maior-que-a-do-afeganistao>. Acesso em: 01 fev. 2012.

CHINCHILLA. Apud. KAHN, Túlio. Polícia Comunitária. Revista do ILANUD, n. 19, São Paulo: Imprensa Oficial, 2002.

CHOUKR, Fauzi Hassan. Código de Processo Penal: comentários consolidados e crítica jurisprudencial. Rio de Janeiro: Lumen Juris, 2005.

Código de Processo Penal: comentários consolidados e crítica jurisprudencial. Rio de Janeiro: Lumen Juris, 2010.

Polícia e Estado de Direito na América Latina: Relatório Brasileiro. In: CHOUKR, Fauzi Hassan; AMBOS, Kai (Coords.). Polícia e Estado de Direito na América Latina. Rio de Janeiro: Lumen Juris, 2004. p. 1-51.

Processo Penal de Emergência. Rio de Janeiro: Lumen Juris: 2002.

COLOMER, Juan-Luis Gómez. Estado democrático e modelo policial: uma proposta de estrutura para obter uma investigação eficaz do crime. In: CHOUKR, Fauzi Hassan; AMBOS, Kai (Coords.). Polícia e Estado de Direito na América Latina. Rio de Janeiro: Lumen Juris, 2004. p. 93-109.

COMPARATO, Fabio Konder. Prefácio. BENEVIDES, Maria Victória. Violência, Povo e Polícia: Violência Urbana no Noticiário de Imprensa. São Paulo: Brasiliense, 1983.

CUBAS, Viviane de Oliveira. A Expansão das Empresas de Segurança Privada em São Paulo. Dissertação (Mestrado em Ciências Sociais). São Paulo: Faculdade de Filosofia, Letras e Ciências Humanas da USP, 2002.

DIAS NETO, Theodomiro. Policiamento comunitário e controle social sobre a polícia: a experiência norte-americana. São Paulo: IBCCRIM, 2000.

DUBOIS, Marc. Educação em direitos humanos para a polícia. In: ANDREOPOULOS, George J.; Claude, Richard Pierre. Educação em direitos humanos para o século XXI. Trad. Ana Luiza Pinheiro. São Paulo: Universidade de São Paulo: Núcleo de Estudos da Violência, 2007. p. 455-484.

ENFIM, um herói do lado certo. Revista Veja. São Paulo, ano 43, n. 45, p. 120-127, 10 nov. 2010. Especial.

EREMIAS DELIZOICOV - Centro de documentação; DOSSIÊ - Mortos e Desaparecidos Políticos no Brasil. Lista de nomes de desaparecidos e mortos políticos. 2002-2007. Disponível em:

<http://www.desaparecidospoliticos.org.br/pessoa.php?id=363\&m=3>. Acesso em: 03 jan. 2012. 
FIA/USP - Fundação Instituto de Administração da Universidade de São Paulo Desenvolvimento e implantação de metodologia de monitoramento e avaliação do Plano de Integração e Acompanhamento de Programas Sociais de Prevenção de Violência - PIAPS/PNSP. Projeto do Programa de Modernização do Poder Executivo Federal, São Paulo, 15 jun. 2001 a 30 nov. 2002. Disponível em:

<http://www.livrosgratis.com.br/arquivos_livros/pl000021.pdf>. Acesso em: 26 nov. 2010.

FISCHER, Rosa Maria. O Direito da População à Segurança: Cidadania e Violência Urbana. Petrópolis, Vozes; São Paulo: Centro de Estudos de Cultura Contemporânea CEDEC, 1985.

FLOWERS, Nancy; SHIMAN, David A. Educação de professores e a visão de direitos humanos. In: ANDREOPOULOS, George J.; Claude, Richard Pierre. Educação em direitos humanos para o século XXI. Trad. Ana Luiza Pinheiro. São Paulo: Universidade de São Paulo: Núcleo de Estudos da Violência, 2007. p. 253-273.

GENEVOIS, Margarida Pedreira Bulhões. Educação e direitos humanos. Disponível em: <http://www.dhnet.org.br/dados/livros/edh/estaduais/rs/adunisinos/margarida.htm>. Acesso em: 13 nov. 2010.

GREENE, Jack. A questão do policiamento comunitário. Revista do Instituto Latinoamericano das Nações Unidas para a Prevenção do Delito e Tratamento do Delinquente - ILANUD, n. 12, p. 25-35, São Paulo, 1998.

GREGORI, José. O Programa Nacional dos Direitos Humanos. Palestra proferida em 20 de agosto de 1996. Disponível em:

<http://www.dhnet.org.br/dados/pp/pndh/pndh.html>. Acesso em: 26 nov. 2010.

KAHN, Túlio. Polícia Comunitária. Revista do ILANUD, n. 19, São Paulo: Imprensa Oficial, 2002.

LA HAYE, Jacques Lesage de. A morte do manicômio: história da antipsiquiatria. São Paulo: Imaginário: Editora da Universidade Federal do Amazonas, 2007.

LOPES, Ronaldo Pantera; MATOS, Kerma Sousa. Um resumo da história da Polícia Civil de carreira. Disponível em:

<http://www2.policiacivil.sp.gov.br/x2016/modules/mastop_publish/?tac=Um_resumo_ da_hist\%F3ria_da_Pol\%EDcia_Civil_de_carreira>. Acesso em: 19 nov 2010.

MATSUDA, Fernanda E.; et al. Afinal, o que é segurança pública? São Paulo: Global, 2009. (Coleção Conexão Juventudes)

MESQUITA NETO, Paulo de. A polícia em face do aumento da criminalidade. Boletim Movimento do Ministério Público Democrático, São Paulo, ano 2, n. 6, p. 11-12, 2003. Disponível em: <http://www.nevusp.org/portugues/index2.php?option=com_content\&do_pdf=1\&id=10 54>. Acesso em: 18 jul. 2011. 
Programa Nacional de Direitos Humanos: continuidade ou mudança no tratamento dos Direitos Humanos no Brasil? Disponível em:

<http://www.dhnet.org.br/direitos/militantes/paulomesquita/mesquita_pndh.html>. Acesso em: 26 nov. 2010.

Segurança, justiça e direitos humanos no Brasil. In: LIMA, Renato Sérgio de;

PAULA, Liana de. Segurança pública e violência: o Estado está cumprindo seu papel? São Paulo: Contexto, 2006. p. 53-64.

MESQUISTA NETO, Paulo de; et al. (coord.). $3^{\mathbf{0}}$ Relatório Nacional de Direitos Humanos. São Paulo: Universidade de São Paulo, Núcleo de Estudos da Violência, 2007.

MESQUITA NETO, Paulo de. O Programa Estadual de Direitos Humanos: Uma Oportunidade para Controlar a Violência e Promover a Cidadania. Disponível em: <http://www.dhnet.org.br/direitos/militantes/paulomesquita/mesquita_pedhsp.html>. Acesso em 01 dez. 2010a.

Programa Nacional de Direitos Humanos: continuidade ou mudança no tratamento dos Direitos Humanos no Brasil?. Disponível em:

<http://www.dhnet.org.br/direitos/militantes/paulomesquita/mesquita_pndh.html>. Acesso em: 26 nov. $2010 \mathrm{~b}$.

MICHAUD, Yves. Apud. MINGARDI, Guaracy. Tiras, Gansos e Trutas. São Paulo: Editora Página Aberta, 1992.

MINGARDI, Guaracy. Tiras, Gansos e Trutas. São Paulo: Editora Página Aberta, 1992.

MOCCIA, Sergio. Apud. CHOUKR, F. H. Processo Penal de Emergência. Rio de Janeiro: Lumen Juris: 2002.

MONET, Jean-Claude. Apud. ZACCARIOTTO, José Pedro. A Polícia Judiciária no Estado Democrático. Sorocaba: Brazilian Books, 2005.

MONTORO, André Franco. Cultura dos direitos humanos, Revista do Instituto Latinoamericano das Nações Unidas para a Prevenção do Delito e Tratamento do Delinquente - ILANUD, n. 12, p. 25-35, São Paulo, 1998.

MORAES, Paulo Roberto Santana de. Direitos Humanos e Polícia Militar: uma Visão dos Policiais Militares em Atuação na Cidade de Salvador. In: ZENAIDE, Maria de Nazaré T. (org.). A Formação em Direitos Humanos na Universidade: Ensino, Pesquisa e Extensão. João Pessoa: Editora Universitária / UFPB, 2006. p.-p.

MUÑOZ, Vernor. EI mar entre la niebla: El camino de la educación hacia los derechos humanos. San José, Costa Rica: Litografía e Imprenta, 2009.

NEME, Cristina. A polícia é um indicativo da democracia. Entrevista para o Fórum Brasileiro de Segurança Pública e para o portal da Comunidade Segura. 2 mar. 2011. 
Disponível em: <http://www.comunidadesegura.org/pt-br/MATERIA-a-policia-e-umindicativo-de-como-anda-a-nossa-democracia>. Acesso em: 8 nov. 2011.

Relatório 15 anos da Ouvidoria da Polícia. São Paulo: Ouvidoria da Polícia do Estado de São Paulo, Imprensa Oficial, 2011. Disponível em: <ftp://ftp.sp.gov.br/ftpouvidoria-policia/Cartilha\%2015\%20anos.pdf>. Acesso em: 04 jan. 2012.

NEVES, José Luis. Pesquisa qualitativa: características, uso e possibilidades. Caderno de pesquisas em administração, São Paulo, v. 1, n. 3, 2º semestre, 1996.

NEVES, Paulo S. C. Direitos Humanos, Universidade e Intervenção Social:

Democratizando as Instituições Policiais. In: ZENAIDE, Maria de Nazaré T. (org.). A

Formação em Direitos Humanos na Universidade: Ensino, Pesquisa e Extensão. João Pessoa: Editora Universitária / UFPB, 2006. p.-p.

OBSERVATÓRIO de Segurança Pública: boas práticas no Estado de São Paulo. A Segurança Pública no Brasil. Disponível em:

<http://www.observatoriodeseguranca.org/seguranca>. Acesso em 20 jul. 2011.

OLIVEIRA, Luciano. Violência brasileira e direitos humanos: a razão iluminista contra a parede. In: BITTAR, Eduardo; TOSI, Giuseppe. (orgs.). Democracia e educação em direitos humanos numa época de insegurança. Brasília: Secretaria Especial dos Direitos Humanos da Presidência da República, 2008. p. 267-276.

PAIXÃO, Antônio Luiz. Apud. MINGARDI, Guaracy. Tiras, Gansos e Trutas. São Paulo: Editora Página Aberta, 1992.

PIMENTEL, Alessandra. O método da análise documental: seu uso numa pesquisa historiográfica. Cadernos de Pesquisa, Departamento de Psicologia Social e Institucional da Universidade Estadual de Londrina - PR, n. 114, p. 179-195, nov. 2001. Disponível em: <http://www.scielo.br/pdf/cp/n114/a08n114.pdf>. Acesso em: 16 nov. 2010.

PINHEIRO, Paulo Sérgio; MESQUITA NETO, Paulo de. Programa Nacional de Direitos Humanos: avaliação do primeiro ano e perspectivas. Estudos Avançados, São Paulo, vol. 11, n. 30, mai.-ago. 1997. Disponível em:

<http://www.scielo.br/scielo.php?script=sci_arttext\&pid=S0103-

40141997000200009\&lang=pt>. Acesso em: 1 dez. 2010.

PLANO Nacional de Segurança Pública. Brasília. 2000. Disponível em: <http://www.dhnet.org.br/3exec/novapolicia/plano_segpub.htm >. Acesso em: 28 nov. 2010.

SALLA, Fernando; et al. (coord.). $4^{\mathbf{0}}$ Relatório Nacional sobre os Direitos Humanos no Brasil. São Paulo: Universidade de São Paulo; Núcleo de Estudos da Violência, 2010 .

SALLA, Fernando. A Crise na Segurança Pública no Brasil. 2006. Disponível em: <http://www.nevusp.org/downloads/down143.pdf>. Acesso em: 15 out. 2008. 
De Montoro a Lembo: as políticas penitenciárias em São Paulo. 2007.

Disponível em: <http://www.nevusp.org/downloads/down157.pdf>. Acesso em: 16 jul. 2011.

SALLA, Fernando; PIOVESAN, Flávia. Tortura no Brasil: pesadelo sem fim? Ciência Hoje, São Paulo, outubro 2001, vol. 30, n. 176, p. 30-33.

SÃO PAULO. Centro de Direitos Humanos e Segurança Pública. Academia de Polícia Civil do Estado de São Paulo. Relatório de Atividades. São Paulo, SP, 2006, 33 p.

CONSEGs, Conselhos Comunitários de Segurança. Secretaria de Estado da Segurança Pública. Disponível em: 〈http://www.conseg.sp.gov.br/conseg/default.aspx>. Acesso em: 30 abr. 2010a.

Lei Complementar n. 207, de 05 de janeiro de 1979. Institui a Lei Orgânica da Polícia do Estado de São Paulo. Governo do Estado de São Paulo. Secretaria da Segurança Pública. Polícia Civil do Estado de São Paulo. Disponível em: <http://www2.policiacivil.sp.gov.br/x2016/modules/smartsection/item.php?itemid=9>. Acesso em : 15 mar. 2010.

Polícia Civil do Estado de São Paulo. Disponível em: $<$ http://www2.policiacivil.sp.gov.br/x2016/modules/mastop_publish/?tac=ACADEPOL $>$. Acesso em: 16 mar 2011.

Secretaria da Justiça e da Defesa da Cidadania. Programa Estadual de Direitos Humanos. 1997. Disponível em: <http://www.justica.sp.gov.br/Modulo.asp?Modulo=480\&Cod=2>. Acesso em: $01 \mathrm{dez}$. 2010.

Secretaria de Segurança Pública do Estado de São Paulo. Disponível em: <http://www.ssp.sp.gov.br/institucional/historico/default.aspx>. Acesso em: 26 abr. $2010 b$.

SCHILLING, Flávia. Apresentação. In: MATSUDA, Fernanda E.; et al. Afinal, o que é segurança pública? São Paulo: Global, 2009. (Coleção Conexão Juventudes)

Corrupção, crime organizado e democracia. Revista Brasileira de

Ciências Criminais, São Paulo, v. 36, 2001. Disponível em: $<$ https://bvc.cgu.gov.br/bitstream/123456789/2603/1/corrupcao_crime_organizado_dem ocracia.pdf $>$. Acesso em: 15 out. 2010.

Educação em direitos humanos: reflexões sobre o poder, a violência e a autoridade na escola. Universitas Psychologica, Bogotá, v.7, n.3, Sep. - Dec. 2008. Disponível em: <http://www.scielo.org.co/scielo.php?script=sci_arttext\&pid=S165792672008000300007\&lang=pt>. Acesso em: 15 out. 2010.

O direito à educação: um longo caminho. In: BITTAR, Eduardo C. B. (coord.). Educação e metodologia para os direitos humanos. São Paulo: Quartier Latin, 2008. p. 273-284. 
O Estado do mal-estar: corrupção e violência. São Paulo em Perspectiva, São Paulo, 1999, p. 47-55. Disponível em:

<http://www.scielo.br/pdf/spp/v13n3/v13n3a06.pdf>. Acesso em: 16 jan. 2012

SILVA, Carlos Afonso Gonçalves da. O ensino de direitos humanos na polícia civil de São Paulo: aspectos formacionais da Academia de Polícia, desafios e perspectivas. 2007. 227 f. Tese (Doutorado em Direito do Estado). Pontifícia Universidade Católica de São Paulo.

SOARES, Luiz Eduardo. A Política Nacional de Segurança Pública: histórico, dilemas e perspectivas. Estudos avançados, vol. 21, n. 61, São Paulo, 2007. Disponível em: <http://www.scielo.br/scielo.php?script=sci_arttext\&pid=S0103-40142007000300006>. Acesso em 03 jan 2012.

Apud. MATSUDA, Fernanda E.; et al. Afinal, o que é segurança pública? São Paulo: Global, 2009. (Coleção Conexão Juventudes)

SOUZA, Luís Antônio Francisco de. Autoridade, violência e reforma policial: a polícia preventiva através da historiografia de língua inglesa. Estudos Históricos, Rio de Janeiro, vol. 12, n. 22, 1998, p. 265-294.

Lei, cotidiano e cidade: polícia civil e práticas policiais na São Paulo Republicana (1889-1930). São Paulo: IBCCRIM, 2009.

TARGIONI, Paolo. Abandono dos direitos humanos na era da globalização. In: MARTINS, Rosana; et al. (Orgs.). Direitos humanos, segurança pública e comunicação. São Paulo: ACADEPOL, 2007. p.29-35.

TAVARES, Celma. Educar em direitos humanos, o desafio da formação dos educadores numa perspectiva interdisciplinar. In: SILVEIRA, Rosa Maria Godoy; et all. Educação em direitos humanos: fundamentos teórico-metodológicos. João Pessoa: Editora Universitária, 2007. p. 487-503.

TOSI, Giuseppe; SILVA, Marlene Helena Oliveira. Por que punir? Qual punição? Que segurança Pública? In: NEVES, Paulo Sérgio da Costa; et al. (Orgs.). Polícia e democracia: desafios à educação em direitos humanos. Recife: Gajop; Bagaço, 2002. p. 241-257.

TREVISAN, Leonardo. A República Velha. Disponível em:

http://www.culturabrasil.pro.br/republicavelha.htm. Acesso em: 17 nov. 2010.

UNESCO - Organização das Nações Unidas para a educação, a ciência e a cultura.

Educação um tesouro a descobrir. Relatório da Comissão Internacional sobre a educação no século XXI. 2010. Disponível em: <http://unesdoc.unesco.org/images/0010/001095/109590por.pdf>. Acesso em 14 dez. 2011.

VALENTIM, Daniela Rodrigues; MANDELLI JR.; Roberto Mendes. Convenção Americana de Direitos Humanos. Disponível em: 
<http://www.pge.sp.gov.br/centrodeestudos/bibliotecavirtual/direitos/tratado7.htm>. Acesso em: 5 out. 2010.

VIEIRA, Hermes; SILVA, Oswaldo. História da polícia civil de São Paulo. São Paulo: companhia Editora Nacional, 1955. (5 Série da Coleção Brasiliana da Biblioteca Pedagógica Brasileira)

VIEIRA, Hermes. Formação Histórica da Polícia de São Paulo. São Paulo: Serviço Gráfico da Secretaria da Segurança Pública: Escola de Polícia, 1965.

ZACCARIOTTO, José Pedro. A Polícia Judiciária no Estado Democrático.

Sorocaba: Brazilian Books, 2005.

ZAFFARONI, E. Raúl; et al. Direito Penal Brasileiro: Teoria Geral do Direito Penal. 2 ed. Rio de Janeiro: Revan, 2003. 1 v.

ZENAIDE, Maria de Nazaré Tavares. Introdução. In: SILVEIRA, Rosa Maria Godoy; et all. Educação em direitos humanos: fundamentos teórico-metodológicos. João Pessoa: Editora Universitária, 2007. p. 15-25. 